\title{
Formation and Gas Barrier Characteristics of Polysilazane-Derived Silica Coatings Formed by Excimer Light Irradiation on PET Films with Vacuum Evaporated Silica Coatings
}

\author{
Tomoji Ohishi*, Yoshimi Yamazaki \\ Department of Applied Chemistry, Faculty of Engineering, Shibaura Institute of Technology, Koto-ku, Tokyo, Japan \\ Email: *tooishi@sic.shibaura-it.ac.jp
}

How to cite this paper: Ohishi, T. and Yamazaki, Y. (2017) Formation and Gas Barrier Characteristics of Polysilazane-Derived Silica Coatings Formed by Excimer Light Irradiation on PET Films with Vacuum Evaporated Silica Coatings. Materials Sciences and Applications, 8, 1-14. http://dx.doi.org/10.4236/msa.2017.81001

Received: December 1, 2016

Accepted: December 25, 2016

Published: December 28, 2016

Copyright ( 92017 by authors and Scientific Research Publishing Inc. This work is licensed under the Creative Commons Attribution International License (CC BY 4.0).

http://creativecommons.org/licenses/by/4.0/

(c) (i) Open Access

\begin{abstract}
The effects of excimer light irradiation on polysilazane coatings formed on PET films with vacuum-evaporated $\mathrm{SiO}_{2}$ coatings and the effects of these coatings on gas barrier characteristics have been investigated. The temperature during light irradiation has a large effect on the coating's molecular structure and gas barrier characteristics. When irradiation was performed at $100^{\circ} \mathrm{C}$, the polysilazane coating transformed into a silica coating, and a compact silica coating at a much lower temperature than with heat treatment alone was produced. Surface irregularities in the vapor-deposited silica coating were smoothed out by the formation of a polysilazane coating, which was transformed into a compact silica coating when irradiated with light, resulting in a significant improvement in the gas barrier characteristics. The water vapor permeability of the thin coating irradiated with excimer light at $100^{\circ} \mathrm{C}$ showed only $0.04 \mathrm{~g} / \mathrm{m}^{2}$.day $\left(40^{\circ} \mathrm{C}, 90 \% \mathrm{RH}\right)$. According to the results of investigation of temperature variation of water-vapor permeability, it is inferred that the developed film has an excellent gas barrier value, namely, $4.90 \times 10^{-4}$ $\mathrm{g} / \mathrm{m}^{2}$.day at $25^{\circ} \mathrm{C}$. This gas barrier coated PET film is transparent and flexible, and can be used in the fabrication of flexible electronics. Also, the proposed fabrication method effectively provides a simple low-cost and low-temperature fabrication technique without the need for high vacuum facility.
\end{abstract}

\section{Keywords}

Polysilazane, Photo-Irradiation, Excimer Light, Gas Barrier Characteristics, PET Film, Flexible Electronics 


\section{Introduction}

For the next generation of electronic products, attention has recently turned to products with flexible properties such as wearable devices, flexible batteries, electronic paper and flexible display devices that are thin, light and flexible [1]-[6]. There are also strong expectations of developments in flexible electronic devices that are needed to make these products. An essential component of flexible electronics is a flexible substrate on which various devices can be formed. Flexible substrates are generally made using flexible organic resin films. However, ordinary organic films have poor gas barrier characteristics against oxygen, water vapor and the like. This can result in problems such as oxidation of various devices formed on these films, leading to serious performance degradation issues. Consequently, there is a strong demand for the development of flexible substrates that have good gas barrier characteristics. One way of improving the gas barrier characteristics of an organic film is to add a compact inorganic coating, but the low heat tolerance of organic films makes it difficult to form an inorganic gas barrier coating with adequate performance. What is needed is a simple method for the formation of dense inorganic coatings on organic films with low heat tolerance.

The most common material for organic films is polyethylene terephthalate (PET). Attempts have been made to improve the gas barrier characteristics of this material by applying inorganic coatings. The heat tolerance of PET is about $100^{\circ} \mathrm{C}$, and the most popular way of forming an $\mathrm{SiO}_{2}$ coating is to use large-scale high vacuum deposition facility to implement deposition methods such as vacuum deposition or sputtering with a reduced level of substrate heating [7]-[12]. However, coatings formed in this way still have insufficient gas barrier characteristics, and are costly to produce because they require the use of complex high vacuum facility. A simpler method involves coating with an inorganic precursor solution, but since this precursor solution has to be heated to several hundred degrees centigrade $\left({ }^{\circ} \mathrm{C}\right)$ to form a compact inorganic coating, this method is unsuitable for organic films with low heat tolerance [13] [14] [15] [16] [17].

Another method that has been studied recently involves applying polysilazane coatings to PET films, which are then exposed to excimer light irradiation or ultraviolet ray irradiation [18]-[26]. This method is able to form compact inorganic coatings at low temperature, and has been used to develop organic films with reasonably good gas barrier characteristics. This method has attracted interest for the production of low-cost printed electronics, since it uses a coating that can be applied by printing an inorganic precursor solution. However, there have been no reports on the effect of applying excimer light irradiation while heating. The polysilazane-derived $\mathrm{SiO}_{2}$ barrier films on PET film, which were irradiated with excimer lamp at room temperature without heating, show the values of water vapor transmission rate (WVTR) of $0.7 \mathrm{~g} / \mathrm{m}^{2}$.day [21] and 0.2 $\mathrm{g} / \mathrm{m}^{2}$.day [25]. But the values of WVTR are insufficient to apply these gas barrier films for electronic devices. By irradiating a polysilazane coating with ultraviolet light from a low-pressure mercury lamp while heating, we have successfully de- 
veloped an alicyclic polyimide film that has good gas barrier characteristics, high heat tolerance and high transparency, and a PET film with high gas barrier performance [27] [28] [29]. In this study, we formed a gas barrier film by applying a polysilazane coating to a PET film with a vapor deposited silica coating, and then irradiating with ultraviolet excimer light irradiation while heating the film. This paper reports on the results of studying the properties of films formed in this way. When a polysilazane coating is formed on a vacuum-evaporated silica coating, it flattens out the surface roughness of the silica coating. This is expected to improve the gas barrier characteristics by repairing surface defects in the inorganic silica coating and making it more compact.

\section{Experimental}

\subsection{Preparation of Silica Coatings by Using Light Irradiation}

As a precursor for forming thin coatings, a solution of polysilazane in dibutyl ether (NL-110, 20 wt\%: AZ Electronic Materials Co.) was used. A 5 wt\% dibutyl ether solution of this polysilazane solution was spin-coated (2000 rpm, $60 \mathrm{sec})$ onto a PET film $(10 \mathrm{~cm} \times 10 \mathrm{~cm} \times$ thickness $100 \mu \mathrm{m}$ : sp51, Nitto Denko Co. $)$ on which $\mathrm{SiO}_{2}$ had been formed by vapor deposition. This film was exposed to light from an excimer lamp (M.D.COM Inc.) in an $\mathrm{N}_{2}$ atmosphere (commercial grade: $\mathrm{O}_{2}<20 \mathrm{ppm}$ ). The film was irradiated at $42 \mathrm{~mW} / \mathrm{cm}^{2}$ for 2 minutes. This irradiation was performed at three different substrate temperatures: room temperature (R.T.), $80^{\circ} \mathrm{C}$ and $100^{\circ} \mathrm{C}$. The coating was applied to one side of the film. Samples were prepared with a single-layer and two-layer polysilazane coatings. To find out how the molecular structure of these coatings changes during heat treatment, samples heat-treated at $80^{\circ} \mathrm{C}, 100^{\circ} \mathrm{C}, 200^{\circ} \mathrm{C}$ and $300^{\circ} \mathrm{C}$ were prepared for infrared spectrum measurements.

\subsection{Characterization}

The changes in the molecular structure of the coatings based on their infrared absorption spectra were observed. The absorption and reflection spectra of the coatings were measured by a visible/ultraviolet spectrophotometer (Shimadzu UV-245). The reflectivity was measured by determining the $5^{\circ}$ specular reflectance after blackening the opposite side of the PET film. The surface of the coating was examined with a scanning electron microscope (SEM: JEOL JSM-7610) and an atomic force microscope (AFM: 5100N, Hitachi Hightech Science Co.). The cross-sectional structure of the coating with a transmission electron microscope (TEM: H-9000NAR, Hitachi Ltd.) was observed. The TEM samples were prepared by FIB (focused ion beam) processing. The elemental analysis (EDX) of the observed cross-sections was performed. To assess the gas barrier characteristics, the water vapor permeability $\left(40^{\circ} \mathrm{C}, 90 \% \mathrm{RH}\right.$ : Mocon Permatran-W) was measured. Water vapor transmission rates of $1 \mathrm{~g} / \mathrm{m}^{2}$.day or above were measured using the dish method. The water vapor permeability was measured at a humidity of $90 \% \mathrm{RH}$ and at temperatures of $40^{\circ} \mathrm{C}, 45^{\circ} \mathrm{C}, 50^{\circ} \mathrm{C}$ and $55^{\circ} \mathrm{C}$. The 
adhesion strength of the coating on the PET film was evaluated by performing tape peeling tests according to the JIS standard (JIS K5600).

\section{Results}

\subsection{Appearance and Transparency of the Gas Barrier Coatings}

The gas barrier coatings were produced by light irradiation at $100^{\circ} \mathrm{C}$ or less, considering the heat tolerance of the PET film. Light irradiation conditions were as follows, light irradiation wavelength: $172 \mathrm{~nm}$, irradiation intensity: 42 $\mathrm{mW} / \mathrm{cm}^{2}$, irradiation time: 2 minutes, irradiation area: $10 \mathrm{~cm} \times 10 \mathrm{~cm}$, respectively. Figure 1 shows the surface appearance and transmittance spectra of PET films with a gas barrier coating. These films are highly transparent. The singlelayer and two-layer coatings both had a transmittance of approximately $87 \%$ $90 \%$ over the visible region from $400-800 \mathrm{~nm}$, which were similar to or even better than that of a PET film or a PET film with a vacuum-evaporated $\mathrm{SiO}_{2}$ coating. The single-layer coating had the highest transmittance. This is thought to be because it also had lower reflectivity than the other films in this region. The surface reflectivity of the single-layer coating was approximately $3 \%-5 \%$ over this wavelength region. It is inferred that the increased transmittance resulted from the suppressed reflectivity. The gas barrier films were also highly flexible, and did not develop cracks or other defects when bent.

The coating exhibited high adhesion strength to the PET film, achieving a value of 100/100 (remaining number of sheets/Number of cuts) in tape peeling tests according to the JIS standard.

\subsection{Changes in the Infrared Spectra of the Polysilazane Coating by Photo Irradiation}

Figure 2 shows the infrared absorption spectra of coatings produced under various conditions. This figure compares the spectra obtained at different substrate

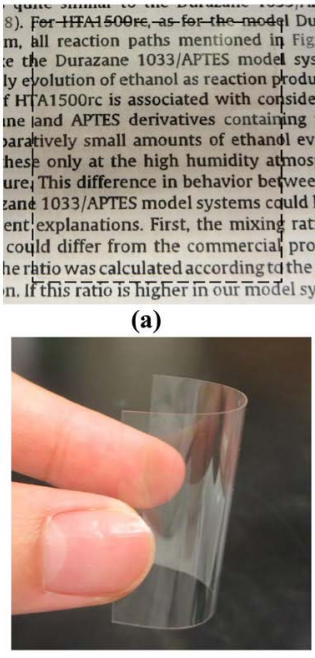

(b)

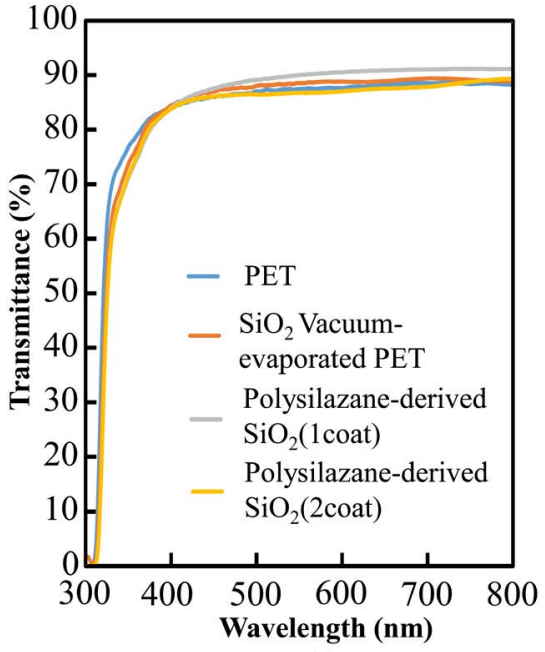

(c)

Figure 1. Appearance and absorption spectra of the gas barrier film prepared by photo irradiation. (a) High transparency; (b) High flexibility; (c) Absorption spectra. 


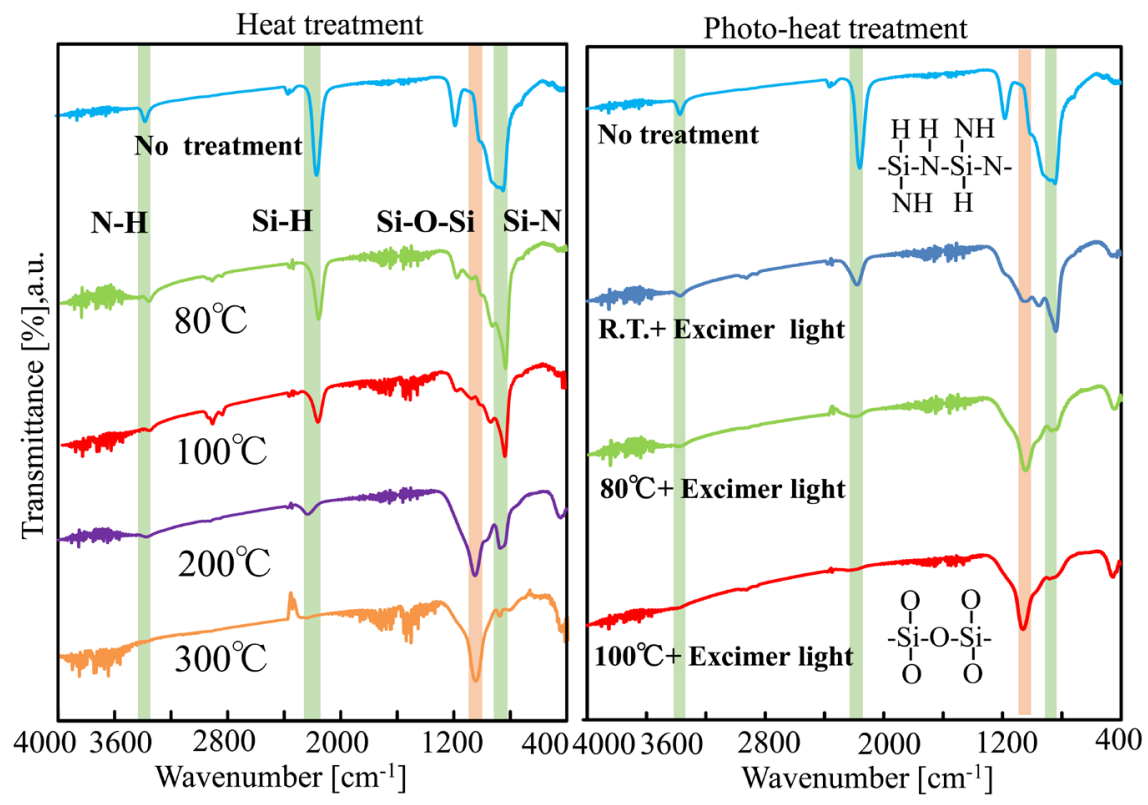

Figure 2. Infrared absorption spectra of polysilazane-derived film prepared by photoirradiation and by heat treatment.

temperatures during irradiation with the spectra of materials produced only by heat treatment.

As for the heat-treated samples, the absorption peaks corresponding to $\mathrm{NH}$ $\left(\sim 3300 \mathrm{~cm}^{-1}\right), \mathrm{SiH}\left(\sim 2200 \mathrm{~cm}^{-1}\right)$ and $\operatorname{SiN}\left(\sim 800 \mathrm{~cm}^{-1}\right)$ were observed directly after the coating had been formed. This suggests that the coating has a structure that includes Si-N bonds due to polysilazane. These absorption peaks decreased as the heat treatment temperature was increased over the range $80^{\circ} \mathrm{C} \rightarrow 100^{\circ} \mathrm{C}$ $\rightarrow 200^{\circ} \mathrm{C} \rightarrow 300^{\circ} \mathrm{C}$, during which there was in increase in the absorption peak near $1100 \mathrm{~cm}^{-1}$ associated with siloxane bonds (-O-Si-O-). When heat treatment is performed at $300^{\circ} \mathrm{C}$, a strong siloxane bond absorption peak is observed, showing that the coating was transformed into $\mathrm{SiO}_{2}$. At $200^{\circ} \mathrm{C}$, there is still an absorption peak corresponding to polysilazane, showing that the transformation into $\mathrm{SiO}_{2}$ is not yet complete. On the other hand, in the coatings that were subjected to simultaneous heat treatment and light irradiation, the absorption peaks corresponding to $\mathrm{NH}\left(\sim 3300 \mathrm{~cm}^{-1}\right), \mathrm{SiH}\left(\sim 2200 \mathrm{~cm}^{-1}\right)$ and $\mathrm{SiN}\left(\sim 800 \mathrm{~cm}^{-1}\right)$ that were observed directly after the coating had been formed decreased greatly as the temperature during light exposure was increased (r.t. $\rightarrow 80^{\circ} \mathrm{C} \rightarrow 100^{\circ} \mathrm{C}$ ), whereas the siloxane (-O-Si-O-) peak around $1100 \mathrm{~cm}^{-1}$ increased. The absorption peaks due to polysilazane were observed in the coating exposed to light at room temperature, but in the coating exposed at $80^{\circ} \mathrm{C}$, these peaks were greatly reduced and the absorption peak near $1100 \mathrm{~cm}^{-1}$ was much larger. In the coating exposed at $100^{\circ} \mathrm{C}$, hardly any polysilazane absorption peak could be observed, indicating that the polysilazane coating had almost completely transformed into $\mathrm{SiO}_{2}$. This shows that simultaneous light exposure and heat treatment can produce silica coatings at much lower temperatures than heat treatment alone. 


\subsection{Observation of Coated Surfaces by SEM and AFM}

The coated surfaces were very smooth, and no differences could be seen in SEM images taken at magnification factors of 10,000 - 20,000x. Therefore SEM observations at $100,000 \times$ magnification and AFM observations of the surface were performed. The results are shown in Figure 3. The SEM observations revealed that the PET surface contained cracks about $5 \mathrm{~nm}$ wide and with lengths ranging from $30-100 \mathrm{~nm}$. Furthermore, the AFM observations revealed surface irregularities with an average roughness $(\mathrm{Ra})$ of approximately $0.44 \mathrm{~nm}$. In the SEM observations, the $\mathrm{SiO}_{2}$ applied to the PET film by vacuum evaporation had the appearance of small particles. AFM observations showed that the surface irregularity was larger than that of the PET surface, with an average roughness (Ra) of $1.2 \mathrm{~nm}$. When a polysilazane coating is formed on this vapor-deposited $\mathrm{SiO}_{2}$ coating, its surface becomes smoother and more compact. AFM observations showed a significant reduction in surface irregularity: $0.32 \mathrm{~nm}$ in the single-layer coating and $0.29 \mathrm{~nm}$ in the two-layer coating. SEM images also show that the surface irregularity observed in the vapor-deposited coating is substantially reduced by the single-layer coating, and that the two-layer coating resulted in a surface that was even smoother and more compact. This is thought to be because when a polysilazane solution is applied to the irregular surface of the vapordeposited coating, the solution is able to penetrate into these irregularities to form a smooth surface. This sort of phenomenon is often observed in the formation of interlayer insulation films in semiconductor devices, where device surfaces are smoothed out by applying a solution in order to form an interlayer insulation coating. Smoothing out the surface of the vacuum-evaporated $\mathrm{SiO}_{2}$ by

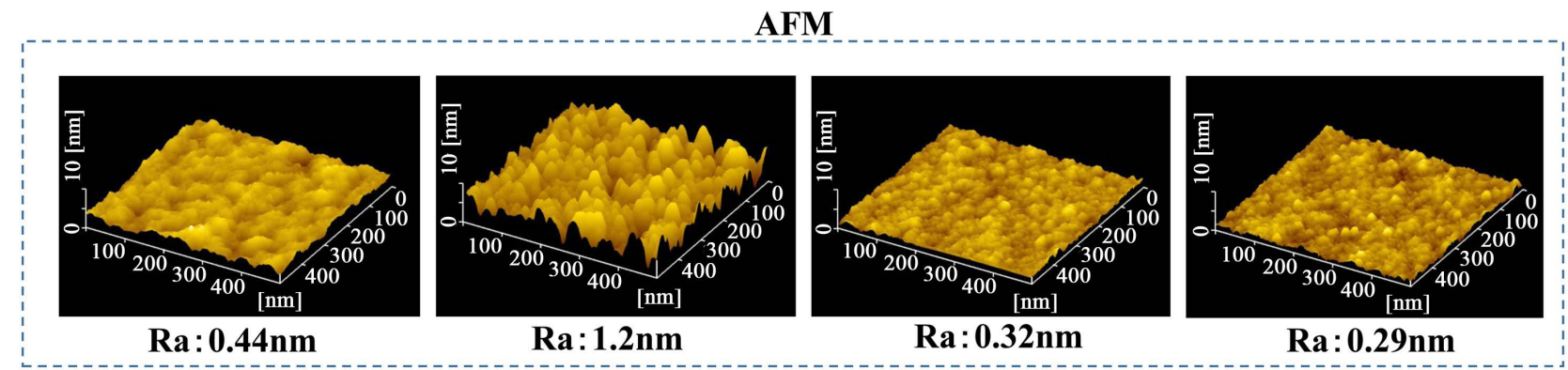

SEM

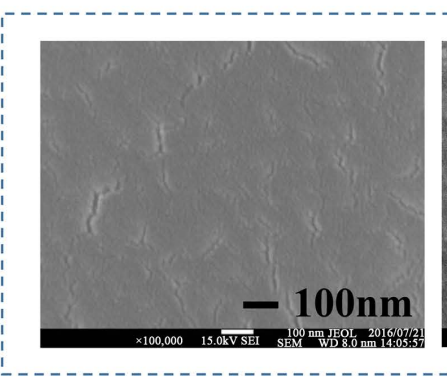

(a)

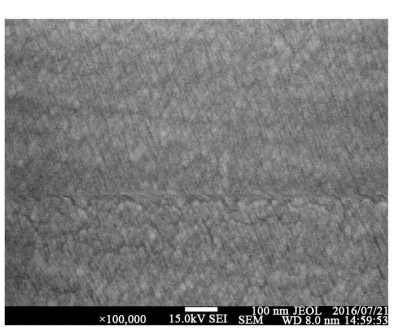

(b)

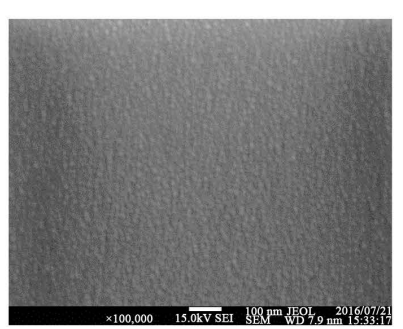

(c)

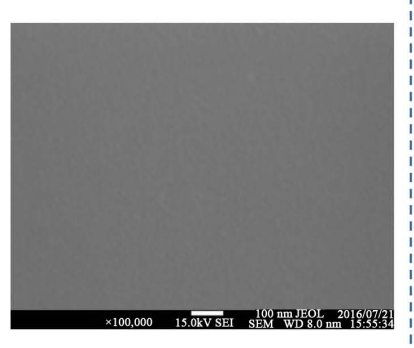

(d)

Figure 3. SEM and AFM images of the gas barrier film prepared by photoirradiation, $\mathrm{SiO}_{2}$ vacuum-evaporated PET and PET. (a) PET; (b) $\mathrm{SiO}_{2}$ evaporated PET; (C) Polysilazane-derived $\mathrm{SiO}_{2}$ (1 coat); (d) Polysilazane-derived $\mathrm{SiO}_{2}$ (2 coat). 
forming a polysilazane coating at low temperature effectively helps to make the surface more compact, resulting in improvement of gas barrier properties of the film.

\subsection{Cross-Sectional Observation of Coatings by TEM}

Figure 4 shows a TEM micrograph of a cross section for the two-layer coating on the $\mathrm{SiO}_{2} / \mathrm{PET}$. A thin vapor-deposited layer of $\mathrm{SiO}_{2}$ (about $20 \mathrm{~nm}$ thick) is formed on the vacuum-evaporated PET film, and on top of that, a layer of polysilazane about $170-180 \mathrm{~nm}$ thick is formed. On the surface of the vapor-deposited coating, the irregularities reflecting the irregularities of the PET surface were observed, but it was found that the formation of a polysilazane coating made the surface smoother. Furthermore, no interface between the single-layer and two-layer coatings was observed, which means they were both integrated into a single structure. The lack of an observable interface between the applied layers of polysilazane coating is consistent with the observations made so far [27] [28]. Figure 5 shows the results of EDX elemental analysis at observation points ${ }^{\star} 1$ through ${ }^{\star} 4$ in the cross-sectional TEM micrograph. Point ${ }^{\star} 1$ is in the PET film substrate, so $\mathrm{C}$ and $\mathrm{O}$ were observed here. Points ${ }^{*} 2$ and ${ }^{*} 3$ are in the silica coating formed from polysilazane, so $\mathrm{Si}$ and $\mathrm{O}$ were observed here. Any $\mathrm{N}$ in this region was not observed, which suggests that the polysilazane coating had transformed into silica. Point ${ }^{\star} 4$ is in the vapor-deposited silica, where $\mathrm{Si}$ and $\mathrm{O}$ indicative of a similar composition to the polysilazane parts were observed. At points ${ }^{\star} 2$ through ${ }^{\star} 4$, small quantities of $\mathrm{C}$ was observed, but these are attributed to contamination by organic substances used in the protective coatings applied when preparing the samples for observation. $\mathrm{W}$ as a constituent of deposition that occurred while preparing the samples for TEM observations, and Ga originating from the FIB ion source were also detected.

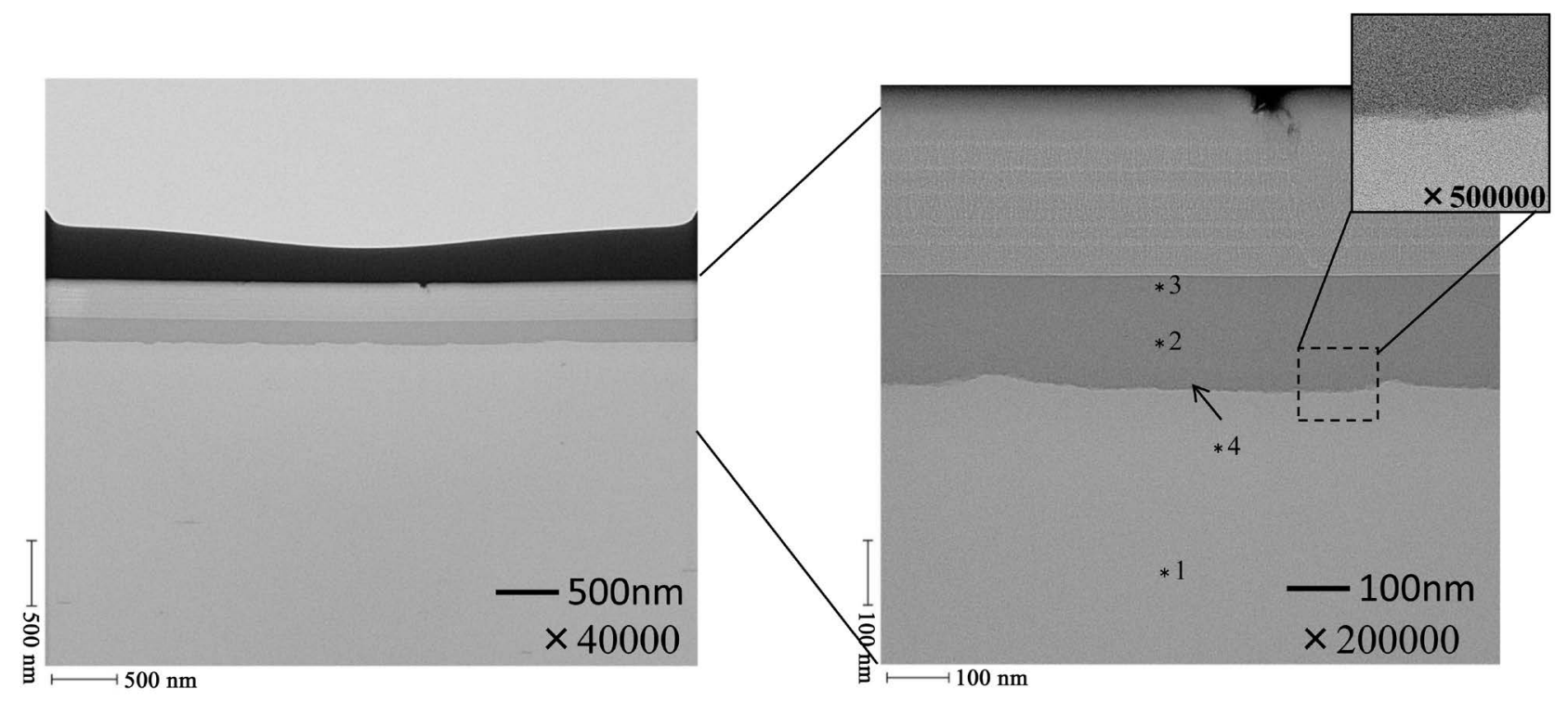

Figure 4. Cross-sectional TEM images of the gas barrier film prepared by photo irradiation (2-coat film). 

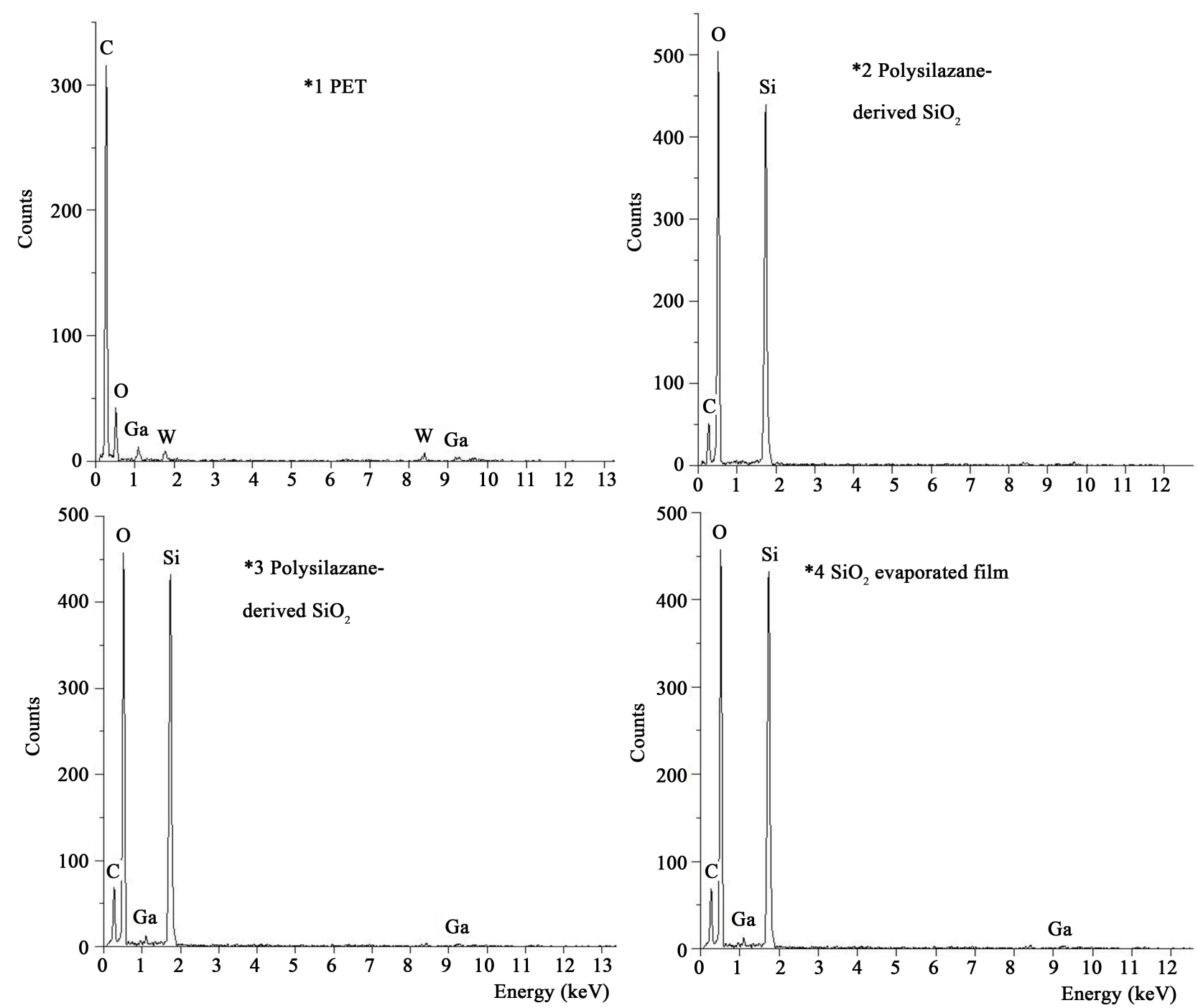

Figure 5. EDX elemental analysis in cross-sectional TEM images of the gas barrier film prepared by photo irradiation (2-coat film).

\subsection{Gas Barrier Property}

Figure 6 compares the water vapor permeabilities of plain PET, PET with vapordeposited $\mathrm{SiO}_{2}$, and PET with a single-layer or two-layer coating of polysilazane. The values of water vapor transmission rate (WVTR) in Figure 6 showed the mean value of five samples, respectively. The formation of an inorganic coating on the surface of the PET improved its water vapor permeability. In descending order, the water vapor permeabilities can be ordered as follows: PET (6.80 $\mathrm{g} / \mathrm{m}^{2}$.day $) \rightarrow \mathrm{SiO}_{2}$ vapor deposited PET $\left(3.20 \mathrm{~g} / \mathrm{m}^{2} \cdot\right.$ day $) \rightarrow$ single-layer coating $\left(1.20 \mathrm{~g} / \mathrm{m}^{2}\right.$.day $) \rightarrow$ two-layer coating $\left(0.04 \mathrm{~g} / \mathrm{m}^{2} \cdot\right.$ day $)$. The two-layer coating resulted in far lower permeability. This order matches the order of increasing surface smoothness and compactness, suggesting that the coating surface state and compactness have a large effect on its gas barrier property. The $\mathrm{SiO}_{2}$ vapor deposited PET had a coating thickness of about $20 \mathrm{~nm}$, and its surface irregularities and other features were larger than those of the polysilazane coatings. It is 


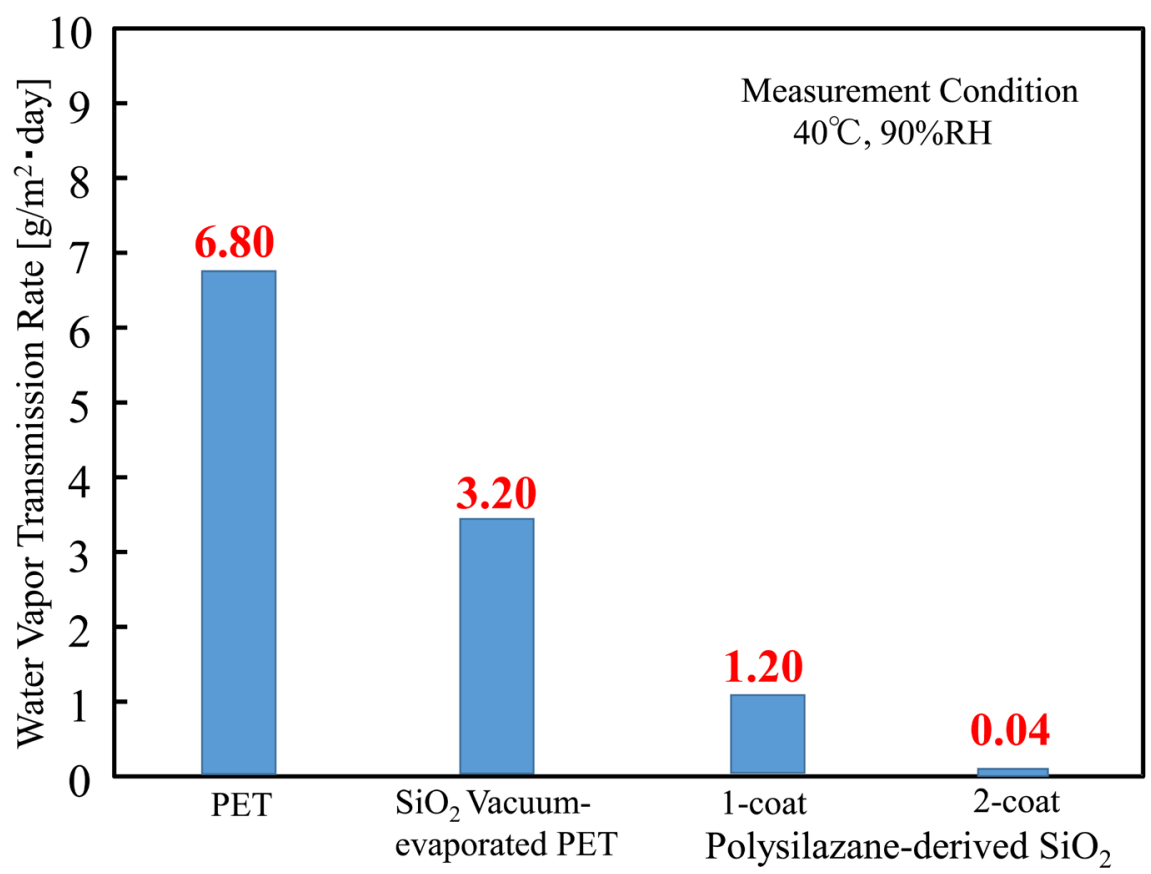

Figure 6. Water vapor transmission rates of the polysilazane-derived $\mathrm{SiO}_{2}$ film, $\mathrm{SiO}_{2}$ vacuum-evaporated PET and PET.

therefore assumed that this is the reason why it did not make a large improvement to the gas barrier characteristics. The application of a polysilazane solution on top of this $\mathrm{SiO}_{2}$ is thought to have covered up defects in the $\mathrm{SiO}_{2}$ vapor-deposited PET coating, resulting in better gas barrier property. The two-layer coated films produced only with heat treatment at $80^{\circ} \mathrm{C}$ and $100^{\circ} \mathrm{C}$ showed almost the same values as the $\mathrm{SiO}_{2}$ vapor deposited PET, and hardly exhibited any reduction in the gas barrier property.

Temperature dependence of water vapor transmission rate of the doublecoating film by photo irradiation at $100^{\circ} \mathrm{C}$ was measured. A natural-log plot of measured water-vapor transmission rate under certain conditions (temperatures of $40^{\circ} \mathrm{C}, 45^{\circ} \mathrm{C}, 50^{\circ} \mathrm{C}$, and $55^{\circ} \mathrm{C}$ and relative humidity of $90 \%$ ) against the reciprocal plot of temperature is shown in Figure 7. Four measurement points (i.e., temperature/water-vapor transmission rate: $40^{\circ} \mathrm{C} ; 0.04 \mathrm{~g} / \mathrm{m}^{2} \cdot$ day, $45^{\circ} \mathrm{C} ; 0.21$ $\mathrm{g} / \mathrm{m}^{2}$.day, $50^{\circ} \mathrm{C} ; 1.20 \mathrm{~g} / \mathrm{m}^{2}$.day, and $55^{\circ} \mathrm{C} ; 2.20 \mathrm{~g} / \mathrm{m}^{2}$.day) are plotted. These values show a linear relation with the reciprocal of temperature in accordance with the Arrhenius equation. The activation energy of water-vapor transmission (obtained from the slope of the straight line by using the Arrhenius equation) is 236 $\mathrm{kJ} / \mathrm{mol}$. Moreover, watervapor transmission at room temperature $\left(25^{\circ} \mathrm{C}\right)-\mathrm{de}-$ termined by extrapolating the line-is given as an extremely low value (i.e., 4.90 $\times 10^{-4} \mathrm{~g} / \mathrm{m}^{2}$.day).

\subsection{Discussion}

Polysilazane has a strong absorption peak in the ultraviolet region below 260 $\mathrm{nm}$, and absorbs vacuum ultraviolet light at the excimer lamp's emission 


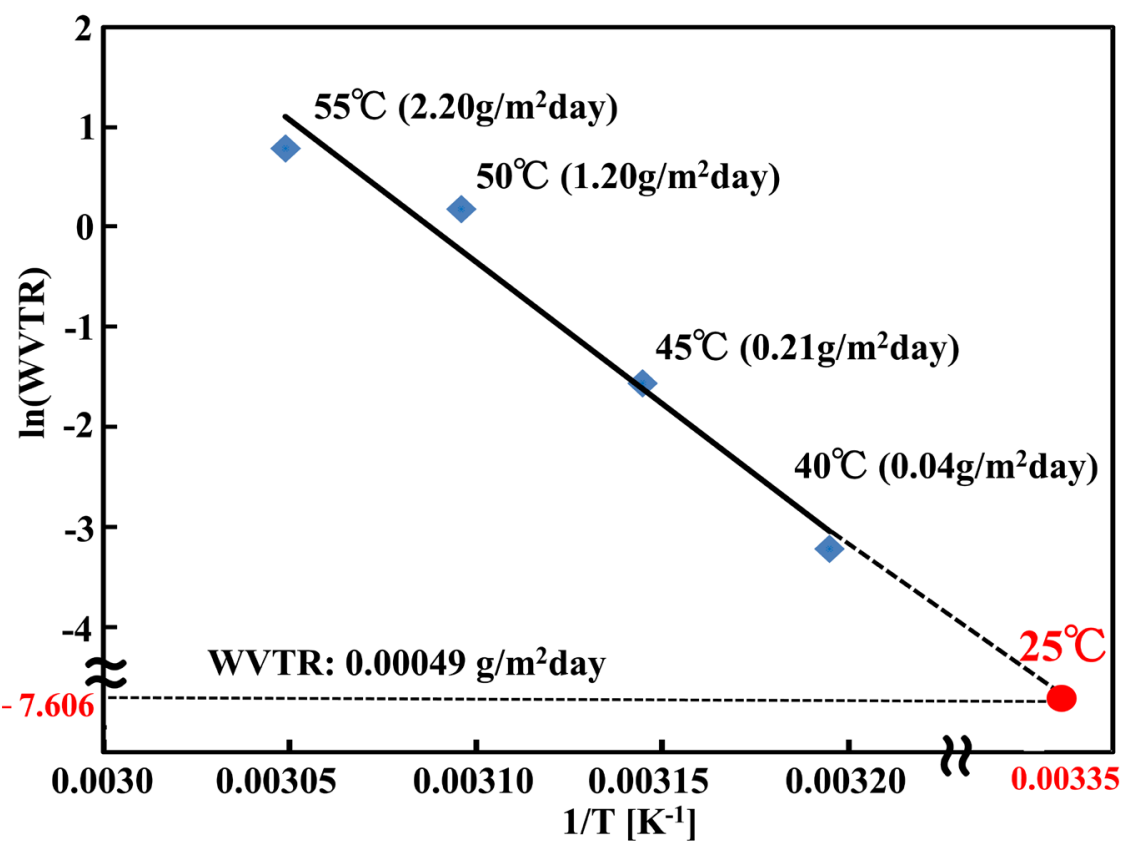

Figure 7. Temperature dependency of water vapor transmission rates of the polysilazanederived $\mathrm{SiO}_{2}$ film (2-coat film).

wavelength of $172 \mathrm{~nm}$. The energy level of light at the excimer lamp's emission wavelength $(172 \mathrm{~nm})$ is $166 \mathrm{kcal} / \mathrm{mol}$. On the other hand, the Si-N, Si-H and $\mathrm{N}-\mathrm{H}$ bond energies of polysilazane are 105,71 and $92 \mathrm{kcal} / \mathrm{mol}$, respectively. Since the energy of the ultraviolet light is greater than these bond energies, it has enough energy to break the polysilazane bonds. Broken bonds are instantly oxidized and transformed into $\mathrm{SiO}_{2}$ by singlet oxygen $\left(\mathrm{O}\left({ }^{1} \mathrm{D}\right)\right)$ or ozone $\left(\mathrm{O}_{3}\right)$ generated when ultraviolet light is absorbed by oxygen present in trace quantities inside the light irradiation chamber or in the inert nitrogen gas. A higher temperature during light irradiation is thought to increase the diffusion of active oxygen species into the coating where it further promotes the oxidation of Si. This can also be seen from the fact that the water vapor permeability and changes in the molecular structure of the polysilazane coating in the infrared absorption spectrum are strongly dependent on the light irradiation temperature.

In the infrared spectra, as the temperature during light irradiation increases, the $\mathrm{N}-\mathrm{H}, \mathrm{Si}-\mathrm{H}$ and $\mathrm{Si}-\mathrm{N}$ absorption peaks originating from polysilazane decrease while the peak corresponding to $\mathrm{Si}-\mathrm{O}-\mathrm{Si}$ bonds originating from $\mathrm{SiO}_{2}$ increases. This confirms that the polysilazane is converted into $\mathrm{SiO}_{2}$ more efficiently as the temperature increases. In the coatings subjected to light irradiation, the transformation into an $\mathrm{SiO}_{2}$ coating has already occurred at $100^{\circ} \mathrm{C}$. Considering that the transformation to $\mathrm{SiO}_{2}$ occurs at $300^{\circ} \mathrm{C}$ with heat treatment alone, this demonstrates the effectiveness of gas barrier films made according to the technique proposed here for the formation of gas barrier coatings at low temperature.

Also, from the elemental analysis results of TEM cross-sectional structure observations, no $\mathrm{N}$ in the coating was found. The coating is thought to consist of $\mathrm{SiO}_{2}$ or $\mathrm{SiO}_{x}$-based silica. In the future, we plan to use XPS to perform a precise 
analysis of the composition ratio of the silica coating.

The gas barrier property of a PET film was improved by the vacuum vapor deposition of silica, but a major improvement was not observed. The formation of a polysilazane-derived $\mathrm{SiO}_{2}$ coating on this vapor-deposited coating promotes increased density and evens out the surface irregularities, resulting in a significant improvement in the gas barrier property. Coatings formed by ordinary vapor deposition or sputtering processes grow by depositing atoms on convex parts of the substrate surface, and are thus liable to form column-shaped structures with surface irregularities. Since gases diffuse more readily along the grain boundaries of these column-shaped structures, this is thought to have an adverse effect on the gas barrier characteristics. The polysilazane coating fills in the surface irregularities of the $\mathrm{SiO}_{2}$ vapor-deposited PET coating with a solution that has a certain molecular weight when the polysilazane solution is applied, and when it hardens, the solvent evaporates away and shrinks in the thickness direction to leave a uniform layer of amorphous silica. Therefore, it is thought that the surface of the vacuum-evaporated $\mathrm{SiO}_{2}$ layer is smoothed out, and that the surface defects are filled in, resulting in better gas barrier property.

The gas-barrier property depends on the formation conditions and thickness of the thin film. It is possible that the gas-barrier property is greatly enhanced by formation of the lamination layers when the substrate temperature is raised during photo-irradiation. The double-coated thin film photo-irradiated at $100^{\circ} \mathrm{C}$ showed a water-vapor transmission rate $\left(0.04 \mathrm{~g} / \mathrm{m}^{2} \cdot\right.$ day $)$ near the measurement limit of the measurement apparatus $\left(0.02 \mathrm{~g} / \mathrm{m}^{2}\right.$.day). The temperature dependence of water vapor permeability shows a linear relation with the reciprocal of temperature in accordance with the Arrhenius equation. The value of water-vapor permeability at $25^{\circ} \mathrm{C}$ calculated from the Arrhenius plot is an extremely low value $\left(4.90 \times 10^{-4} \mathrm{~g} / \mathrm{m}^{2}\right.$.day $)$ and the activation energy is $236 \mathrm{~kJ} / \mathrm{mol}$. The same linear dependence of water vapor permeability was also obtained in PET film. PET film shows the activation energy of $42 \mathrm{~kJ} / \mathrm{mol}$ and the value of water-vapor permeability of $3.10 \mathrm{~g} / \mathrm{m}^{2}$.day at $25^{\circ} \mathrm{C}$, respectively. The developed film shows much larger activation energy than that of PET, indicating excellent gas barrier characteristics.

The gas barrier coatings used in this study were formed on one side only of a PET film. It is expected that a significant improvement in gas barrier performance can be achieved by forming gas barrier coatings on both sides of the film. The polysilazane-derived $\mathrm{SiO}_{2}$ film formed on both side of a PET film (no vacuum-evaporated $\mathrm{SiO}_{2}$ ) by low-pressure mercury lamp showed the WVTR value of $0.03 \mathrm{~g} / \mathrm{m}^{2}$.day $\left(40^{\circ} \mathrm{C}, 90 \% \mathrm{RH}\right)$ [28]. The developed film irradiated with excimer lamp has higher gas barrier property than that of the film by low-pressure mercury lamp. The polysilazane-derived $\mathrm{SiO}_{2}$ barrier films on PET film, which were irradiated with excimer lamp at room temperature without heating, shows the WVTR values of $0.2 \mathrm{~g} / \mathrm{m}^{2}$.day [25] and $0.7 \mathrm{~g} / \mathrm{m}^{2} \cdot$ day [21]. The film formation method by simultaneously applying excimer light irradiation and heat-treatment is an effective way of forming a gas barrier film with high performance. 


\section{Conclusion}

The effects of excimer light irradiation on polysilazane coatings formed on PET films with vacuum-evaporated $\mathrm{SiO}_{2}$ coatings and the effects of these coatings on gas barrier property have been investigated. The temperature during light irradiation has a large effect on the coating's molecular structure and gas barrier property. When irradiation was performed at $100^{\circ} \mathrm{C}$, the polysilazane coating transformed into a silica coating, and a compact silica coating at a much lower temperature than with heat treatment alone was produced. Surface irregularities in the vapor-deposited silica coating were smoothed out by the formation of a polysilazane coating, which was transformed into a compact silica coating when irradiated with light, resulting in a significant improvement in the gas barrier characteristics. The water vapor permeability of a thin coating formed at $100^{\circ} \mathrm{C}$ while irradiating with excimer light was found to be only $0.04 \mathrm{~g} / \mathrm{m}^{2}$ per day $\left(40^{\circ} \mathrm{C}, 90 \% \mathrm{RH}\right)$, which is a good result. According to the results of investigation of temperature variation of water-vapor permeability, it is inferred that the developed film has an excellent gas barrier value, namely, $4.90 \times 10^{-4} \mathrm{~g} / \mathrm{m}^{2}$.day at $25^{\circ} \mathrm{C}$. This gas barrier coated PET film is transparent and flexible, and can be used in the fabrication of flexible electronics. Also, since it can be formed by light irradiation of a polysilazane coating without the need for high vacuum facility, the proposed fabrication method effectively provides a simple low-cost and low-temperature fabrication technique.

\section{Acknowledgements}

This work was supported by JSPS KAKENHI Grant Number 26420711.

\section{References}

[1] White, M.S., Kaitenbrunner, M.G., Istrokowacki, E.D., Gutnichenko, K., Kettlgruber, G., Graz, I., Aazou, S., Ulbricht, C., Egbe, D.A.M., Miron, M.C., Major, Z., Schaber, M.C., Sekitani, T., Someya, T., Bauer, S. and Sariciftci, N.S. (2013) Ultrathin Highly Flexible and Stretchable PLEDs. Nature Photonics, 7, 811-816. https://doi.org/10.1038/nphoton.2013.188

[2] Sekitani, T. and Someya, T. (2011) Human-Friendly Organic Integrated Circuit. Materials Today, 14, 398-407. https://doi.org/10.1016/S1369-7021(11)70184-5

[3] Sekitani, T., Zschieschang, U., Klauk, H. and Someya, T. (2010) Flexible Organic Transistor and Circuits with Extreme Bending Stability. Nature Materials, 9, 10151022. https://doi.org/10.1038/nmat2896

[4] Nomura, K., Ohta, H., Kamiya, T., Hirano, M. and Hosono, H. (2004) RoomTemperature Fabrication of Transparent Flexible Thin-Film Transistors Using Amorphous Oxide Semiconductors. Nature, 432, 488-492. https://doi.org/10.1038/nature03090

[5] Wong, W.S. and Salleo, A. (2009) Flexible Electronics: Materials and Applications. Springer, New York. https://doi.org/10.1007/978-0-387-74363-9

[6] Sekitani, T. and Someya, T. (2010) Stretchable Large-Area Organic Electronics. Advanced Materials, 22, 2228-2246. https://doi.org/10.1002/adma.200904054

[7] Carcia, P.F., Mclean, R.S., Groner, M.D., Dameron, A.A. and George, S.M. (2009) Gas Diffusion Ultrabarriers on Polymer Substrates Using $\mathrm{Al}_{2} \mathrm{O}_{3}$ Atomic Layer De- 
position and SiN Plasma-Enhanced Chemical Vapor Deposition. Journal of Applied Physics, 106, 023533. https://doi.org/10.1063/1.3159639

[8] Yagi, Y. and Akashi, K. (2007) Passivation Films on Organic Film Substrates Designed for Organic Electroluminescence Device. Journal of Vacuum Society of Japan, 50, 735. https://doi.org/10.3131/jvsj.50.735

[9] Hanada, T., Negishi, T., Shiroishi, I. and Shiro, T. (2010) Plastic Substrate with Gas Barrierlayer and Transparent Conductive Oxide Thin Film for Flexible Displays. Thin Solid Films, 518, 3089. https://doi.org/10.1016/j.tsf.2009.09.166

[10] Hata, T. and Nakayama, H. (2008) An Organic Catalytic CVD: Principle, Apparatus and Applications. Thin Solid Films, 516, 558.

https://doi.org/10.1016/j.tsf.2007.06.093

[11] Carcia, P.F., MacLean, R.S., Reilly, M.H., Groner, M.D. and George, S.M. (2006) Catalyst of $\mathrm{Al}_{2} \mathrm{O}_{3}$ Gas Diffusion Barriers Grown by Atomic Layer Deposition on Polymer. Applied Physics Letters, 89, Article ID: 031915. https://doi.org/10.1063/1.2221912

[12] Dameron, A.A., Davidson, S.D., Burton, B.B., Carcia, P.F., MacLean, R.S. and George, S.M. (2008) Gas Diffusion Barriers on Polymer Using Multi Layers Fabricated by $\mathrm{Al}_{2} \mathrm{O}_{3}$ and Rapid $\mathrm{SiO}_{2}$ Atomic Layer Deposition. Journal of Physical Chemistry C, 112, 4573-4580. https://doi.org/10.1021/jp076866+

[13] Brinker, C.J. and Schere, G.W. (1990) Sol-Gel Science. Academic Press, Boston.

[14] Seyferth, D. and Wiseman, G.H. (1984) High-Yield Synthesis of $\mathrm{Si}_{3} \mathrm{~N}_{4} / \mathrm{SiC}$ Ceramic Materials by Pyrolysis of a Novel Polyorganosilazane. Journal of American Ceramic Society, 67, C132-C133. https://doi.org/10.1111/j.1151-2916.1984.tb19620.x

[15] Kamiya, K., Oka, A.I., Nasu, H. and Hashimoto, T. (2000) Comparative Study of Structure of Silica Gels from Different Sources. Journal of Sol-Gel Science \& Technology, 19, 495-499. https://doi.org/10.1023/A:1008720118475

[16] Iwamoto, Y., Sato, K., Kato, T., Inada, T. and Kubo, Y. (2005) A Hydrogen-Perselective Amorphous Silica Membrane Derived from Polysilazane. Journal of European Ceramic Society, 25, 257-264. https://doi.org/10.1016/j.jeurceramsoc.2004.08.007

[17] Funayama, O., Tshiro, Y., Kamo, A., Okumura, M. and Isoda, T. (1994) Conversion Mechanism of Perhydropolysilazane into Silicon Nitride-Base Ceramics. Journal of Material Science, 29, 4883-4888. https://doi.org/10.1007/BF00356538

[18] Ohishi, T. (2003) Gas Barrier Characteristics of a Polysilazane Film Formed on an ITO-Coated PET Substrate. Journal of Non-Crystalline Solids, 330, 248-251. https://doi.org/10.1016/j.jnoncrysol.2003.09.022

[19] Naganuma, Y., Tanaka, S., Kato, C. and Shindo, T. (2004) Formation of Silica Coating from Perhydropolysilazane Using Vacuum Ultraviolet Excimer Lamp. Journal of the Ceramic Society of Japan, 112, 599-603. https://doi.org/10.2109/jcersj.112.599

[20] Prager, L., Dierdorf, G., Liebe, H., Naumov, S., Stojanovic', S., Heller, R., Wennrich, L. and Buchmeiser, M.R. (2007) Conversion of Perhydropolysilazane into a $\mathrm{SiO}_{\mathrm{x}}$ Network Triggered by Vacuum Ultraviolet Irradiation: Access to Flexible, Transparent Barrier Coatings. Chemistry-A European Journal, 13, 8522-8529. https://doi.org/10.1002/chem.200700351

[21] Kobayashi, Y., Yokota, H., Fuchita, Y., Takahashi, A. and Sugawara, Y. (2013) Characterization of Gas Barrier Silica Coating Prepared from Perhydropolysilazane Films by Vacuum Ultraviolet Irradiation. Journal-Ceramic Society Japan, 121, 215218. https://doi.org/10.2109/jcersj2.121.215 
[22] Morlier, A., Cros, S., Garandet, J.-P. and Alberola, N. (2012) Thin Gas-Barrier Silica Layers from Perhydropolisilazane Obtained through Low Temperature Curing: A Comparative Study. Thin Solid Films, 524, 62-66. https://doi.org/10.1016/j.tsf.2012.09.065

[23] Naganuma, Y., Horiuchi, T., Kato, C. and Tanaka, S. (2013) Low-Temperature Synthesis of Silica Coating on a Poly(Ethylene Terephthalate) Film from Perhydropolysilazane Using Vacuum Ultraviolet Light Irradiation. Surface \& Coatings Technology, 225, 40-46. https://doi.org/10.1016/j.surfcoat.2013.03.014

[24] Morlier, A., Cros, S., Garandet, J.-P. and Alberola, N. (2013) Gas Barrier Properties of Solution Processed Composite Multilayer Structures for Organic Solar Cells Encapsulation. Solar Energy Materials and Solar Cells, 115, 93-99.

https://doi.org/10.1016/j.solmat.2013.03.033

[25] Morlier, A., Cros, S., Garandet, J.-P. and Alberola, N. (2014) Structural Properties of Ultraviolet Cured Polysilazane Gas Barrier Layers on Polymer Substrates. Thin Solid Films, 550, 85-89. https://doi.org/10.1016/j.tsf.2013.10.140

[26] Blankenburg, L. and Schrodner, M. (2015) Perhydropolysilazane Derived Silica for Flexible Transparent Barrier Foils Using a Reel-to-Reel Wet Coating Technique: Single- and Multilayer Structures. Surface \& Coatings Technology, 275, 193-206. https://doi.org/10.1016/j.surfcoat.2015.05.019

[27] Ohishi, T., Sone, S. and Yanagida, K. (2014) Preparation and Gas Barrier Characteristics of Polysilazane-Derived Silica Thin Films Using Ultraviolet Irradiation. Materials Sciences and Applications, 5, 105-111. https://doi.org/10.4236/msa.2014.53015

[28] Ohishi, T., Yamazaki, Y. and Nabatame, T. (2016) Preparation, Structure and Gas Barrier Characteristics of Polysilazane-Derived Silica Thin Film Formed on PET by Simultaneously Applying Ultraviolet-Irradiation and Heat-Treatment. Frontiers in Nanoscience and Nanotechnology, 2, 149-154.

[29] Ohishi, T. and Yanagida, K. (2016) Preparation and Gas Barrier Characteristics of Polysilazane-Derived Multi-Layered Silica Thin Films Formed on Alycyclic Polyimide Film Using Ultraviolet Irradiation. Frontiers in Nanoscience and Nanotechnology, 2, 173-178. https://doi.org/10.15761/FNN.1000131

\section{Submit or recommend next manuscript to SCIRP and we will provide best service for you:}

Accepting pre-submission inquiries through Email, Facebook, LinkedIn, Twitter, etc. A wide selection of journals (inclusive of 9 subjects, more than 200 journals)

Providing 24-hour high-quality service

User-friendly online submission system

Fair and swift peer-review system

Efficient typesetting and proofreading procedure

Display of the result of downloads and visits, as well as the number of cited articles

Maximum dissemination of your research work

Submit your manuscript at: http://papersubmission.scirp.org/

Or contact msa@scirp.org 